\title{
A Study of Prevalence and Predictors of Acute Ischemic CVA Patients Admitted to Manipal Teaching Hospital, Pokhara, Nepal
}

\author{
Bishnu Jwarchan ${ }^{1}$, Nikunja Yogi ${ }^{2}$, Suman Adhikari ${ }^{1}$, Prabin Bhandari $^{1}$, SubitaLalchan $^{3}$ \\ ${ }^{1}$ Medical Department of Medicine, Manipal Teaching Hospital, Pokhara, Nepal \\ ${ }^{2}$ Department of Neurosurgery, Manipal Teaching Hospital, Pokhara, Nepal \\ ${ }^{3}$ Department of radiology, Manipal Teaching Hospital, Pokhara, Nepal \\ Correspondence: \\ Dr Bishnu Jwarchan \\ Lecturer,Department of Medicine \\ Manipal Teaching Hospital, Pokhara \\ Phone: 9856072548 \\ Email: jwarchan7@gmail.com
}

\begin{abstract}
Background: According to the World Health Organization (WHO), 15 million people suffer stroke worldwide each year. Of these, 5 million die, and another 5 million are left permanently disabled. Materials and methods: A retrospective hospital based observational study was carried out in patients with ischemic CVA. Modified Ranking Scale (MRS) on the follow up on 30 days after discharge was obtained. MRS 0-2 was categorized and good outcome and MRS 3-6 was categorized as poor outcome. Results: Out of 56 patients studied $33.9 \%$ were less than 60 years of age and $63.1 \%$ were greater than 60 years of age. Male to female ratio was 1.55 . MCA territory infarct was the most common with the frequency of $76.8 \%$. There was significant association of HTN, DM, coronary artery disease and other factors as well with the outcome of the patients. Conclusion: On regards to clinic-social demographic parameters there was statistical significance between the gender of the patient, history of systemic hypertension, history of diabetes mellitus and coronary artery disease and outcome of the patient in 30 days follow up.
\end{abstract}

Key words: metallic axe, head injury, cranial injury

$\Lambda$ Stroke is caused by the interruption of the blood supply to the brain, usually because Ischemic stroke is the most common type of stroke. It is usually caused by a blood clot that blocks or plugs a blood vessel in the brain (Thrombotic or Embolic). Another cause is stenosis, or narrowing of the artery. This can happen because of atherosclerosis, a disease in which plaque builds up inside the arteries. Transient ischemic attacks (TIAs) occur when the blood supply to the brain is interrupted briefly. Having a TIA can mean the patient is at risk for having a more serious stroke.

According to the World Health Organization (WHO), 15 million people suffer stroke worldwide each year. Of these, 5 million die, and another 5 million are left permanently disabled. ${ }^{1}$ It is a second leading cause of death (9.7\% of all deaths) just after cardiovascular diseases. ${ }^{3}$ Although more than $85 \%$ cases reported from developing countries, there is minimal study and also funds for those

42

Date submitted: 11/ 8/2019

Date accepted: 09/12/2019 studies regarding prevention and treatment of stroke in developing countries. ${ }^{4}$ Stroke mortality is higher in Asia where most countries are in developing phase, than in Western Europe, the Americas or Australia, except in the case of some countries such as Japan. ${ }^{5}$

The Jaya Stroke Foundation, a non-governmental organization founded by local Nepalese doctors and family members of stroke patients estimates that 50000 people per year are afflicted with stroke, with 15,000 people dying from stroke annually in Nepal. ${ }^{2}$ Although reported as above research and surveys are yet to be done to determine the exact mortality rate.

Methods and Materials:

A retrospective hospital based observational study was carried out in patients with ischemic CVA from January 2018 to December 2018 with an aim to study the clinical parameters predicting clinical outcome. During the study period 100 cases of ischemic CVA were evaluated from the Medical

egneuro Volume 02, Issue 01, 2020 DOI: https://doi.org10.3126/egn.v2i1.27462 
Inpatient department and Medical ICU of Manipal Teaching Hospital, a tertiary care referral center in western region of Nepal. Forty four patients, who failed to give consent or left the hospital against advice or had a hemorrhagic transformation of Ischemic CVA or patient lost to follow-up, were excluded from the study. Patients with history of ischemic stroke were initially evaluated by the medical resident under the supervision of consultant physician. All the patients underwent a head CT (plain or contrast) and were interpreted by consultant radiologists. Data were collected on a preformed proforma which included the patient and ischemic stroke characteristics (age, sex, history of hypertension, prior stroke, peripheral vascular disease (PVD), diabetes mellitus (DM), coronary heart disease (CHD), dyslipidemia, smoking, family history of stroke, systolic blood pressure, diastolic blood pressure, pulse, history of atrial fibrillation, polycythemia, random blood sugar, total cholesterol, HDL,LDL, TG, hemoglobin, hematocrit, left ventricular hypertrophy, STT changes, LVEF, valvular heart disease, cardiomegaly, prestroke disability and serum magnesium level) as well as physical and neurological assessment and Modified Ranking Scale on the day of admission were assessed. After detailed workup patients were either admitted to medicine ward or ICU or treated conservatively. An informed consent was taken from each patient included in this study. Modified Ranking Scale (MRS) on the follow up on 30 days after discharge was obtained and those who did not show for follow up were excluded. MRS 0-2 was categorized and good outcome and MRS 3-6 was categorized as poor outcome. All data were analyzed using the SPSS software for Windows (version 20, SPSS Inc., Chicago, IL, USA). Data were expressed using descriptive statistics such as mean, standard deviation for continuous variables, frequency, and percentage for categorical variables. Statistical analysis was done using Chi square or Fischer exact for categorical and unpaired t test for continuous variable with 5\% significance level. All the clinical predictors found to have statistical significant differences in between good and poor outcome in bivariate analysis were subjected to logistic regression.

egneuro Volume 02, Issue 01, 2020

\section{Results:}

Out of 56 patients studied $33.9 \%$ were less than 60 years of age and $63.1 \%$ were greater than 60 years of age. Male to female ratio was 1.55. MCA territory infarct was the most common with the frequency of $76.8 \%$ whereas $10.7 \%$ patient had ACA territory infract and $12.5 \%$ patient had PCA territory infarct. $53.6 \%$ patients were previously diagnosed as hypertensive and were under antihypertensive medications. $48.2 \%$ patients had diabetes mellitus and were under medication.

The purpose of this study was to study various clinico-socio-demographic parameters, physical findings and lab findings and their effect on the outcome of the ischemic CVA patients.

On regards to clinic-social demographic parameters, statistical significance between the gender of the patient, history of systemic hypertension, history of diabetes mellitus and coronary artery disease and outcome of the patient in 30 days follow up as illustrated in table 1.

On regards to physical findings and lab parameters, statistical significance between dyslipidemia, prestroke disability, carotid stenosis and outcome of the patient in 30 days follow up as illustrated in table 2 .

There was no statistical significance between the ischemic territory involved and the outcome of the patient as shown in table 3 .

\section{Discussion:}

Stroke is the second leading cause of death worldwide. In the USA stroke is the fifth leading cause of mortality. Indian ethnicity Stroke mortality rates seems to be two to three times higher than in the white population. ${ }^{6}$

In addition to high mortality rate in stroke patients, the burden due to disability has significant emotional, social and economic burden to the individual, family, society and country as a whole.

Longer life expectancy among women compared to men has been linked to the higher incidence of stroke related events among women. Therefore stroke has a greater effect on women than men. But 
age specific stroke rates are higher among men than women. ${ }^{7}$

On our study incidence of stroke among men is higher than women with ratio of $1.55 .34(60.7 \%)$ patients were male and $22(39.3 \%)$ patients were Table 1: Outcome of various demographic parameters and physical findings

\begin{tabular}{|c|c|c|c|c|}
\hline S.N & Variables & $\begin{array}{l}\text { Good Outcome (\%) } \\
\text { (MRS 0-1) }\end{array}$ & $\begin{array}{l}\text { Poor Outcome (\%) } \\
\text { (MRS 2-6) }\end{array}$ & P Value \\
\hline \multirow[t]{2}{*}{ Age } & $<60$ & 63.2 & 36.8 & 0.259 \\
\hline & $>60$ & 43.2 & 56.8 & \\
\hline \multirow[t]{2}{*}{ Sex } & Male & 32.4 & 67.6 & $0.001 *$ \\
\hline & Female & 77.3 & 22.7 & \\
\hline \multirow[t]{2}{*}{ HTN } & Absent & 84.6 & 15.4 & $<0.001 *$ \\
\hline & Present & 20.0 & 80.0 & \\
\hline \multirow{2}{*}{ Prior Stroke } & Absent & 49.0 & 51.0 & 1.000 \\
\hline & Present & 57.1 & 42.9 & \\
\hline \multirow[t]{2}{*}{ Peripheral vascular disease } & Absent & 43.5 & 56.5 & 0.36 \\
\hline & Present & 80.0 & 20.0 & \\
\hline \multirow[t]{2}{*}{$\mathrm{DM}$} & Absent & 69.0 & 31.0 & $0.003 *$ \\
\hline & Present & 29.6 & 70.4 & \\
\hline \multirow[t]{2}{*}{ CAD } & Absent & 70.3 & 29.7 & $<0.001 *$ \\
\hline & Present & 10.5 & 89.5 & \\
\hline \multirow[t]{2}{*}{ Smoking } & Absent & 52.0 & 48.0 & 0.788 \\
\hline & Present & 48.4 & 51.6 & \\
\hline \multirow[t]{2}{*}{ Family Hx } & Absent & 55.0 & 45.0 & 0.237 \\
\hline & Present & 37.5 & 62.5 & \\
\hline \multirow[t]{2}{*}{ Polycythemia } & Absent & 55.6 & 44.4 & 0.093 \\
\hline & Present & 27.3 & 72.7 & \\
\hline \multirow{2}{*}{ VHD } & Absent & 48.0 & 52.0 & 0.788 \\
\hline & Present & 51.6 & 48.4 & \\
\hline
\end{tabular}

HTN: Hypertension, DM: Diabetes Mellitus, CAD: Coronary Artery Disease, VHD: Valvular Heart Disease

Table 2: Outcome compared with various physical findings and lab parameters.

\begin{tabular}{|c|c|c|c|c|}
\hline S.N & Variables & $\begin{array}{l}\text { Good Outcome (\%) } \\
\text { (MRS 0-1) }\end{array}$ & $\begin{array}{l}\text { Poor Outcome (\%) } \\
\text { (MRS 2-6) }\end{array}$ & P Value \\
\hline \multirow[t]{2}{*}{ Dyslipidemia } & Absent & 74.1 & 25.9 & \multirow{2}{*}{$0.001 *$} \\
\hline & Present & 27.6 & 72.4 & \\
\hline \multirow[t]{2}{*}{ Left ventricular hypertrophy } & Absent & 41.7 & 58.3 & \multirow{2}{*}{0.280} \\
\hline & Present & 56.2 & 43.8 & \\
\hline \multirow[t]{2}{*}{ STT changes } & Absent & 46.7 & 53.3 & \multirow{2}{*}{0.592} \\
\hline & Present & 53.8 & 46.2 & \\
\hline \multirow[t]{2}{*}{ Cardiomegaly } & Absent & 46.7 & 53.3 & \multirow{2}{*}{0.592} \\
\hline & Present & 53.8 & 46.2 & \\
\hline \multirow[t]{2}{*}{ Atrial fibrillation } & Absent & 82.4 & 17.6 & \multirow{2}{*}{$0.001 *$} \\
\hline & Present & 35.9 & 64.1 & \\
\hline \multirow[t]{2}{*}{ Prestroke disability } & $0-2$ & 70.4 & 29.6 & \multirow{2}{*}{$0.007^{*}$} \\
\hline & $3-6$ & 31.0 & 69.0 & \\
\hline \multirow{3}{*}{ Carotid Stenosis } & $<50$ & 56.7 & 43.3 & \multirow{3}{*}{$0.043^{*}$} \\
\hline & $50-70$ & 55.0 & 45.0 & \\
\hline & $>70$ & 0.00 & 100.0 & \\
\hline
\end{tabular}


Table 3: Outcome of various arterial territorry

\begin{tabular}{lllll}
\hline S.N & Variables & $\begin{array}{l}\text { Good Outcome(\%) } \\
(\text { MRS 0-1) }\end{array}$ & $\begin{array}{l}\text { Poor Outcome (\%) } \\
(\text { MRS 2-6) }\end{array}$ & P Value \\
\hline Territory & ACA & 50.0 & 50.0 & 0.531 \\
& MCA & 46.5 & 53.5 & \\
& PCA & 71.4 & 28.6 & \\
\hline
\end{tabular}

ACA: Anterior cerebral artery, MCA: Middle cerebral artery, PCA: Posterior cerebral artery

Table 4: Confidence Interval of Various Variables

\begin{tabular}{lllll}
\hline Variables & B & S.E. & \multicolumn{2}{c}{ 95\% C.I.for EXP(B) } \\
\cline { 3 - 5 } & & & Lower & Upper \\
\hline Sex(1) & -3.282 & 1.942 & .001 & 1.687 \\
PVD(1) & -.505 & 3.578 & .001 & 670.284 \\
hypertension(1) & -5.512 & 2.537 & .000 & .583 \\
DM(1) & -2.381 & 3.394 & .000 & 71.598 \\
CAD(1) & -1.235 & 1.858 & .008 & .000 \\
Dyslipidemia(1) & -3.460 & 2.151 & .000 & 1.883 \\
AF(1) & -6.516 & 3.648 & .949 & 3.087 \\
RBS & .016 & .035 & .016 & .122 \\
PrestrokeDisability(1) & -.275 & 1.970 & .000 &. \\
Carotid_Stenosis & & & .000 &. \\
Carotid_Stenosis(1) & -24.497 & 11735.479 & \\
Carotid_Stenosis(2) & -27.316 & 11735.480 & 11735.481 & \\
Constant & 32.385 & &
\end{tabular}

Previous studies suggest that the quality of life and functional outcome to be poorer among females because of older age of onset and tendency to suffer more severe stroke as compared to male. ${ }^{7,8,9}$ But our study showed there to be a better outcome among female patients than male patients with the $\mathrm{p}$ value of 0.001 on the 30 day follow up. It could be possible due to presence of ischemic CVA population only in our study vs. all stroke patients in previous studies. The other reason could be due to a shorter follow up period of 30 days in our study vs. a longer follow up periods in other studies. However, female gender was not an independent factor for negative outcome. ${ }^{14}$ Also the pathophysiology of ischemic stroke may be different between male and female population. ${ }^{14}$

There are various risk factors associated with stroke incidence out of which it is further categorized as modifiable and non-modifiable risk factors as tabulated in table 4. Modification of these risk factors are associated with decrease incidence of stroke. ${ }^{10}$ Modification of these risk factors can be achieved via pharmacotherapy (antihypertensive, lipid lowering medications, antiplatelets and anti-coagulants) ${ }^{11}$ and life style modifications(exercise, reduced dietary sodium and fat intake and weight loss). ${ }^{12}$ Gradual accumulation of modifiable risk factors increase the incidence of stroke over time. ${ }^{13}$ In our study, we studied Hypertension, Type II DM, Dyslipidemia, CAD, Smoking, Family history, Prior Stroke, AF, Carotid Stenosis, Polycythemia, VHD, PVD, ECG and Structural Heart Changes. Out of which there was statistical significance between HTN, DM, Coronary Artery Disease, Dyslipidemia, AF and Carotid Stenosis as shown in table 1 and 2.

High blood pressure is the most prevalent modifiable risk factor for stroke. ${ }^{15}$

However our study did not find any statistical significance between smoking, family history of stroke, polycythemia, valvular heart disease, peripheral vascular disease, structural heart changes and history of prior stroke. This could be 
possible due to the smaller sample size in our study.

\section{Modifiable Risk Factors}

Established

Hypertension

Type II DM

Hyperlipidemia

Atrial Fibrillation

Smoking

Overweight and

Obesity

Metabolic Syndromes

Carotid Artery

Diseases Not Established

Hyperhomocysteinemia

Hypercoagulable States
Non-Modifiable Risk Factors

High Age

Male Sex

Nonwhite

ethnicity/Race

Family history of

Stroke

Menopause

\section{Conclusion:}

On regards to clinic-social demographic parameters there was statistical significance between the gender of the patient, history of systemic hypertension, history of diabetes mellitus and coronary artery disease and outcome of the patient in 30 days follow up.

On regards to physical findings and lab parameters there was statistical significance between the dyslipidemia, prestroke disability, carotid stenosis and outcome of the patient in 30 days follow up.

More work is required in Nepal regarding the epidemiological studies of stroke. Adequate epidemiological studies will bring forward the true status of the disease in our setting and also help to legislate programs to reduce disease burden both at human resource and economic level.

\section{Refrences:}

1. World Health Organization. Available at http://www.who.int/ cardiovascular_diseases/en/cvd_atlas_15_burden_stroke.p df (accessed 10 October 2011)

2. Pandit A, Arjyal A, Farrar J, Basnyat B. Nepal. PractNeurol. 2006; 6:129-33.

3. Mathers CD, Ma Fat D, Boerma JT: The Global Burden of Disease: 2004 Update. Geneva, World Health Organization, 2008.

4. Feigin VL: Stroke epidemiology in the developing world. Lancet. 2005;365:2160-2161
5. Feigin VL, Forouzanfar MH, Krishnamurthi R, Mensah GA, Connor M, Bennett DA, et al. Global Burden of Diseases and Risk Factors Study 2010 (GBD 2010) and the GBD Stroke Experts Group Global and regional burden of stroke during 1990-2010: findings from the Global Burden of Disease Study 2010. Lancet. 2014; 383:245-254.

6. Biswas M, Sen S, Simmons J. Etiology and risk factors of ischemic stroke in Indian-American patients from a hospital-based registry in New Jersey, USA. Neurology Asia. 2009 Dec 1;14(2).Reeves MJ, Bushnell CD, Howard G, Gargano JW, Duncan PW, Lynch G, Khatiwoda A, Lisabeth L. Sex differences in stroke: epidemiology, clinical presentation, medical care, and outcomes. The Lancet Neurology. 2008 Oct 1;7(10):915-26.

7. Petrea RE, Beiser AS, Seshadri S, Kelly-Hayes M, Kase CS, Wolf PA. Go Red for Women. Stroke. 2009 Apr; 40(4).

8. Haast RA, Gustafson DR, Kiliaan AJ. Sex differences in stroke. Journal of Cerebral Blood Flow \& Metabolism. 2012 Dec; 32(12):2100-7.

9. Wolf PA, D'Agostino RB, Belanger AJ, Kannel WB. Probability of stroke: a risk profile from the Framingham Study. Stroke. 1991;22:312-318. [PubMed] [Google Scholar]

10. Leys D, Deplanque D, Mounier-Vehier C, MackowiakCordoliani MA, Lucas C, Bordet R. Stroke prevention: management of modifiable vascular risk factors. $\mathrm{J}$ Neurol. 2002; 249:507-517. [PubMed] [Google Scholar]

11. NSA. Stroke Prevention: Controllable Risk Factors. National Stroke Association: Centennial, CO; [Google Scholar]

12. Seshadri S, Beiser A, Kelly-Hayes M, Kase CS, Au R, Kannel WB, et al. The lifetime risk of stroke: estimates from the Framingham Study. Stroke. 2006; 37:345350. [PubMed] [Google Scholar]

13. Caso V, Paciaroni M, Agnelli G, Corea F, Ageno W, Alberti A, Lanari A, Micheli S, Bertolani L, Venti M, Palmerini F. Gender differences in patients with acute ischemic stroke. Women's Health. 2010 Jan;6(1):51-7.

14. Arima H, Chalmers J, Woodward M, Anderson C, Rodgers A, Davis $\mathrm{S}$, et al. Lower target blood pressures are safe and effective for the prevention of recurrent stroke: the PROGRESS trial. J Hypertens. 2006;24:12011208. [PubMed] [Google Scholar] 